\title{
Acute myocardial infarction associated with the induction of general anesthesia
}

\author{
Murathan Küçük ${ }^{1}$, Necmettin Korucuk ${ }^{2}$, Veysel Tosun ${ }^{3}$, Fatma Ertuğrul ${ }^{4}$, Aytül Belgi Yıldırım ${ }^{1}$ \\ ${ }^{1}$ Department of Cardiology, Akdeniz University School of Medicine, Antalya, Turkey \\ ${ }^{2}$ Department of Cardiology, Erciş State Hospital, Van, Turkey \\ ${ }^{3}$ Department of Cardiology, Şanlıurfa Training and Research Hospital, Şanluurfa, Turkey \\ ${ }^{4}$ Department of Anesthesia and Reanimation, Akdeniz University School of Medicine, Antalya, Turkey
}

DOI: $10.18621 /$ eurj.349353

\begin{abstract}
Perioperative acute myocardial infarction (AMI) is the most common cause of postoperative morbidity and mortality. It is a rare but important and fatal complication. Recognizing this situation may be difficult due to the influence of general anesthesia. Early diagnosis and treatment can decrease the morbidity and mortality of this fatal complication. In this case we present a 56-year-old female planned nephrectomy. After induction of general anesthesia acute inferoposterior myocardial infarction occurred and coronary angiograhy showed the proximal portion of the circumflex coronary artery $(\mathrm{Cx})$ was occluded by thrombus, the left anterior descending coronary artery and the right coronary artery were plaque. Percutaneous transluminal coronary angioplasty and the stenting resulted in successful dilatation of the $\mathrm{Cx}$ and she was discharged at the fifth day of intervention without any complication.
\end{abstract}

Keywords: Myocardial infarction, general anesthesia, perioperative care

Received: November 5, 2017; Accepted: December 21, 2017; Published Online: March 12, 2018

$\mathbf{P}$ erioperative acute myocardial infarction (AMI) is the most common cause of postoperative morbidity and mortality $[1,2]$. It is a rare but can be a fatal complication $[3,4]$. It was reported that the mortality of perioperative myocardial infarction was $\% 30-50$ [3]. Although there are many risk factors for development of perioperative AMI such as surgical and anesthetic risk factors according to patient situation, it may occur without any conventional risk factors. Especially two distinct mechanisms can cause perioperative AMI; the first, atherosclerotic plaque rupture and the second, supply-demand imbalance in myocardial oxygen [1]. Several factors can contribute to atherosclerotic plaque rupture in perioprerative period. Physiological and emotional stresses are known to be predisposing factors for AMI. The high levels of the catecholamines and the cortisol after hemodynamic changes, pain, surgical intervention, anemia and hypothermia result in increased heart rate, blood pressure and vascular shear stress. All these situations can lead to plaque instability [5-8]. Also it is known that some anesthetic agents sensitizes the myocardium to the catecholamines [9, 10]. Early diagnosis and treatment of this situation can decrease the morbidity and mortality despite recognizing may be difficult due to the influence of general anesthesia. 


\section{CASE PRESENTATION}

A 56-year-old female admitted to urology department of our hospital and was diagnosed the right nonfunctioning kidney with the repetitive urinary tract infection. For this reasons the nephrectomy operation was planned. The patient has not been using any drugs regularly and had no cardiovascular risk factors such as hypertension, diabetes, hyperlipidemia, smoking, family history. She had a suspected transient ischemic attack 2 years ago but not documented. Preoperative electrocardiograpy (ECG) showed the sinus rhythm with right bundle branch block (Figure 1a). The functional capacity of the patient was NYHA class I and her hemodynamics values were normal (110/70 $\mathrm{mmHg}$, 72/beats). The preoperative cardiology consultation was not requested so no treatment was given perioperatively. In the operating room she was premedicated with midazolam $(0.01-0.1 \mathrm{mg} / \mathrm{kg})$, induction of anesthesia was done with thiopental sodium $(5-6 \mathrm{mg} / \mathrm{kg})$, fentanyl $(0.2 \mu \mathrm{g} / \mathrm{kg})$, rocuronium $(0.6 \mathrm{mg} / \mathrm{kg})$ and it continued with desflurane as a volatile inhalation and remifentanil infusion. After intubation, the patient has bradycardia (40 beats/min) and hypotension (70-75 $\mathrm{mmHg}$ systolic) with ST segment elevation in DII lead. Immediately resuscitated with norepinephrine and saline infusions to normalized the blood pressure. The 12-lead ECG showed ST segment elevation in inferior leads and depression in V1-3 (Figure 1b).

The echocardiographic examination revealed that left ventricular dysfunction with ejection fraction of $40-45 \%$, hypokinetic inferior and posterior wall without any pericardial effusion. Acute inferoposterior myocardial infarction was diagnosed and the patient was immediately transported to the catheterization laboratory in about ten minutes. The angiography showed that the proximal portion of the circumflex coronary artery $(\mathrm{Cx})$ was occluded by thrombus, the left anterior descending coronary artery (LAD) and the right coronary artery (RCA) were plaque. Percutaneous transluminal coronary angioplasty (PTCA) and the bare metal stent implantation resulted in successful dilatation of the $\mathrm{Cx}$ and the ST changes improved instantly (Figure 2).

The patient was taken to the coronary intensive care unit and extubated after three hours after the intervention. On third day, the echocardiographic examination repeated and left ventricular ejection fraction was $\% 55$, other findings were similar with

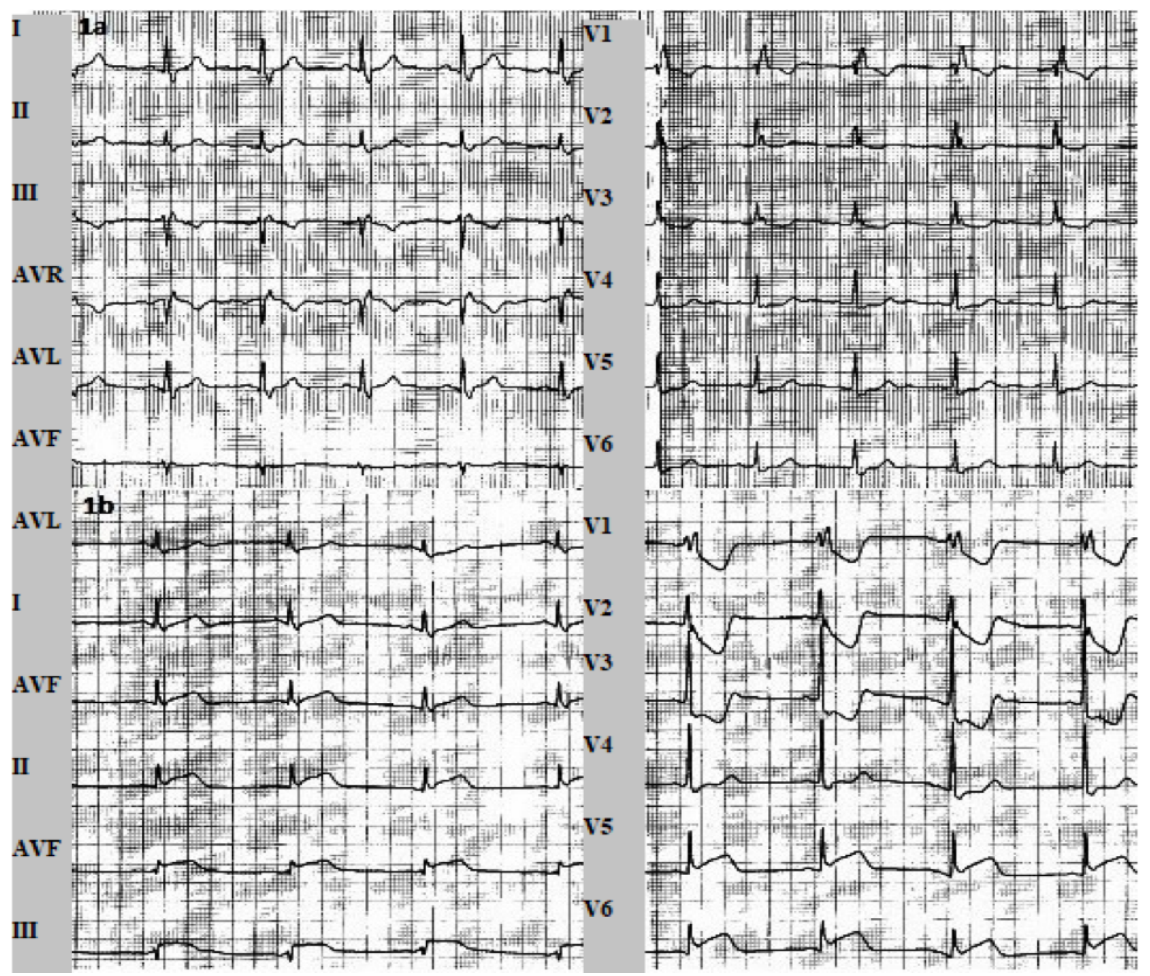

Figure 1. Sinus rhythm with right bundle branch block (a). ST segment elevation in inferior leads and depression in V1-3 (b). 


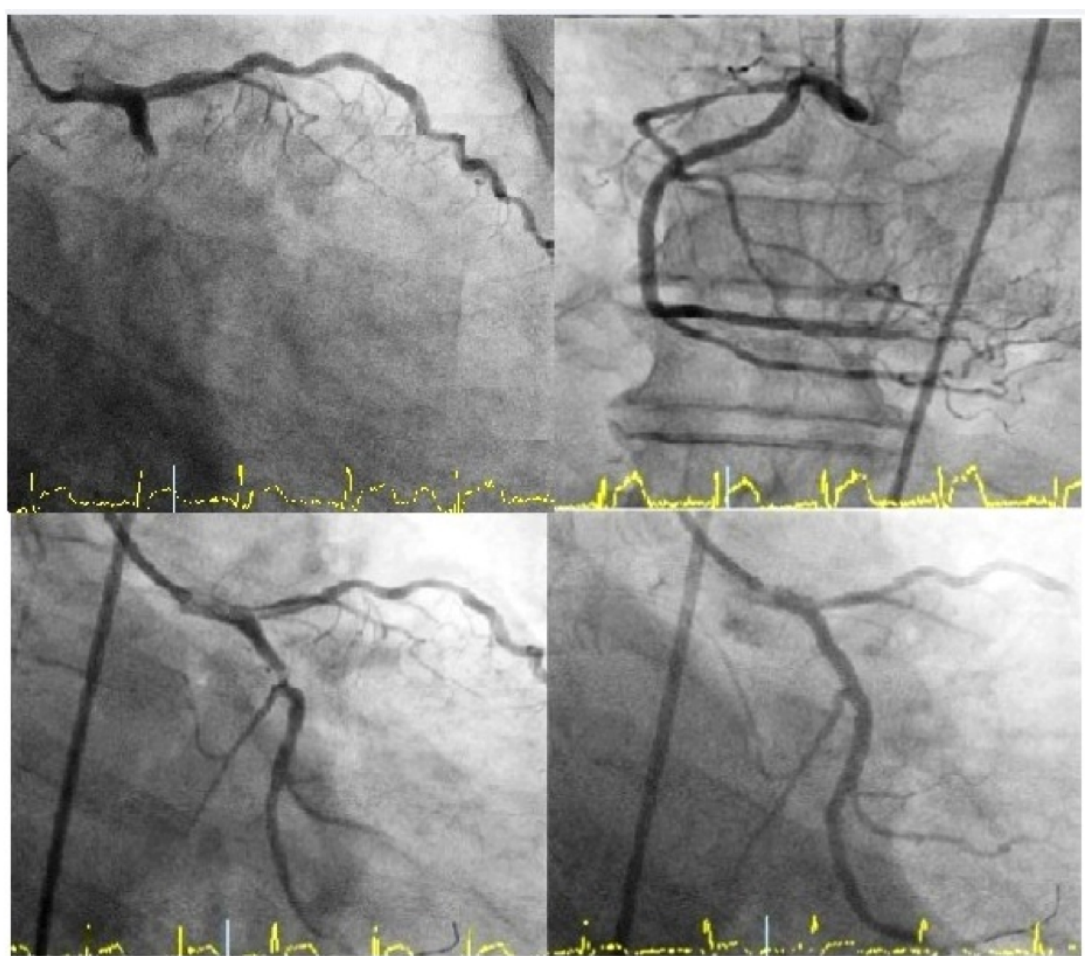

Figure-2. Proximal portion of the Cx was occluded, LAD and RCA were plaque. PTCA and the stenting resulted in successful dilatation of the $\mathrm{Cx}$.

better wall movements. Her nephrectomy operation postponed 6 months later because of this acute coronary syndrome. She was discharged at the fifth day of admission without any complication.

\section{DISCUSSION}

Perioperative AMI, is a rare but can be a fatal complication $[3,4]$. Several factors can cause the myocardial ischemia in perioperative period. Martinez et al. [11] reported that the optimization of supplydemand balance in myocardial oxygen decreased the mortality rate in sixth months. The patients with abnormal preoperative ECG findings such as in our case, have more cardiovascular risk than those with normal ECG findings [12]. Hence, it is important to evaluate the preoperative ECG as a marker of cardiac diseases before operation. In our case, no cardiology recommendations were taken. It is known that some agents (beta blockers, statins etc.) used in perioperative period can decrease such complications. Also monitorization of ST segment is effective in detecting ischemia and prevent infarct in perioperative period [13]. As in our case, the close monitoring of ST segment and the hemodynamic values are very important to recognize AMI during the operation despite to the influence of general anesthesia. Because of increasing levels of the catecholamines and the cortisol after hemodynamic changes or as a result from pain, surgical trauma, anemia and hypothermia, heart rate, blood pressure and vascular shear stress can increase and these conditions can lead to plaque instability [5-8]. Also it is well known that some anesthetic agents such as halothane sensitizes the myocardium to the catecholamines $[9,10]$. It was reported that the adrenaline and the noradrenaline stimulate platelet aggregation such as thromboxane $\mathrm{A}_{2}$, ADP and collagen. For these reason, it can be said that high levels of perioperative adrenaline and noradrenaline might cause to cardiac complications. Thereby ventricular arrhytmias and other adverse events such as perioperative AMI, can be seen during the surgical stress period.

\section{CONCLUSION}

Such as in our case, it can be said that preoperative cardiac evaluation and recommendations must be 
taken in suspicious patients also close monitoring of the hemodynamic parameters and the ST segment during surgical procedures is very important for recognizing perioperative cardiac complications which is the most common cause of postoperative morbidity and mortality. Early diagnosis and treatment of these complications can decrease the morbidity and mortality.

\section{Informed consent}

Written informed consent was obtained from the patient for the publication of this case report.

\section{Conflict of interest}

The authors declared that there are no potential conflicts of interest with respect to the research, authorship, and/or publication of this article.

\section{REFERENCES}

[1] Landesberg G, Beattie WS, Mosseri M, Jaffe AS, Alpert JS. Perioperative myocardial infarction. Circulation 2009;119:2936-44.

[2] Lee TH, Marcantonio ER, Mangione CM, Thomas EJ, Polanczyk CA, Cook EF, et al. Derivation and prospective validation of a simple index for prediction of cardiac risk of major non-cardiac surgery. Circulation 1999; 100:1043-9.

[3] Haagensen R, Steen PA. Perioperative myocardial infarction. Br J Anaesth 1988;61:24-37.

[4] Mangano DT. Perioperative cardiac morbidity. Anesthesiology 1990;72:153-84.

[5] Breslow MJ, Parker SD, Frank SM, Norris EJ, Yates H, Raff H, et al. Determinants of catecholamine and cortisol responses to lower extremity revascularization. PIRAT Study Group. Anesthesiology 1993;79:1202-9.
[6] Chernow B, Alexander HR, Smallridge RC, Thompson WR, Cook D, Beardsley D, et al. Hormonal responses to graded surgical stress. Arch Intern Med 1987;147:1273-8.

[7] Frank SM, Higgins MS, Breslow MJ, Fleisher LA, Gorman RB, Sitzmann JV, et al. The catecholamine, cortisol, and hemodynamic responses to mild perioperative hypothermia: a randomized clinical trial. Anesthesiology 1995;82:83-93.

[8] Fukumoto Y, Hiro T, Fujii T, Hashimoto G, Fujimura T, Yamada J, et al. Localized elevation of shear stress is related to coronary plaque rupture. J Am Coll Cardiol 2008;51:645-50.

[9] Katz RL, Bigger JT. Cardiac arrhythmias during anesthesia and operation. Anesthesiology 1970;33:193-213.

[10] Rodrigo MRC, Moles TM, Lee PK. Comparison of the incidence and nature of cardiac arrhythmias occurring during isoflurane or halothane anesthesia. Studies during dental surgery. Br J Anaesth 1986;58:394-400.

[11] Martinez E, Kim L, Rosenfeld B, Faraday N, Bass E, Perler B, et al. Early detection and real-time intervention of postoperative myocardial ischemia: the STOPMI (Study for the Treatment of Perioperative Myocardial Ischemia) Study. Abstract presented at Association of University Anesthesiologists; May 16-18, 2008; Durham, NC.

[12] Noordzij PG, Boersma E, Bax JJ, Feringa HH, Schreiner F, Schouten $\mathrm{O}$, et al. Prognostic value of routine preoperative electrocardiography in patients undergoing noncardiac surgery. Am J Cardiol 2006;97:1103-6.

[13] Fleisher LA, Nelson AH, Rosenbaum SH. Postoperative myocardial ischemia: etiology of cardiac morbidity or manifestation of underlying disease? J Clin Anesth 1995;7:97-102.

[14] Kimura Y, Okuda H. Effects of alpha- and beta-adrenergic antagonists on epinephrine- induced aggregation and intracellular free calcium concentration in human platelets. Biochem Biophys Res Commun 1994;202:1069-75.

[15] Wu KK. Platelet activation mechanism and markers in arterial thrombosis. J Int Med 1996;239:17-34.

[16] Baldassare D, Mores N, Colli S, Pazzucconi F, Sitori CR, Tremoli E. Platelet alpha2-adrenergic receptors in hypercholesterolemia: relationship between binding studies and epinephrine-induced platelet aggregation. Clin Pharmacol Ther 1997;61:684-91.

[17] Alanko J, Riutta A, Mucha I, Kerttula T, Kaukinen S, Vapaatalo H, et al. Adrenaline stimulates thromboxane and inhibits leukotriene synthesis in man. Eicosanoids 1992;5:169-75. 